\title{
PLM Reference Model: A Preliminary Proposal for Reference Model Evolution
}

\author{
Eduardo Zancul \\ Universidade de Sao Paulo, Escola Politecnica, Departamento de Engenharia de Produção \\ ezancul@usp.br
}

\begin{abstract}
The adoption of product lifecycle management (PLM) business approach requires the implementation of PLM systems. Currently there is a wide variety of PLM systems in the market, but the scope differences between existing systems hamper the selection process for manufacturing companies. This paper presents a reference model for PLM systems and discusses a preliminary proposal for the evolution of this model. The main expected applications for the model are: serve as the basis for the comparison of different commercial systems on selection processes at the industry; contribute to the definition of the theoretical scope of PLM systems; serve as reference for software companies to prioritize the inclusion of new features in their systems.
\end{abstract}

Keywords: Product Lifecycle Management, Reference Model, PLM Systems.

\section{Introduction}

Product Lifecycle Management (PLM) is an approach to integrated management of business processes and information related to products. Such an approach requires the use of integrated information systems, called PLM systems, to support collaboration in extended enterprise, throughout the life cycle.

PLM systems offer many features that support both the creation of product data (e.g. creation of product structures) and the management of product data generated with the support of other systems (e.g. CAD models).

The adoption of PLM systems in manufacturing companies depends on the identification and selection of an appropriate system to meet companies' specific business processes requirements. Nowadays, a wide variety of PLM systems is offered commercially. Recent market research has identified more than 50 commercially available systems [1-2]. Each of these systems covers a slightly different scope and therefore can offer different functionalities according to its origin and its historical evolution, as well as depending on the market focus of the software supplier.

In this scenario, the selection of a PLM system by a manufacturing company is an activity that demands a great amount of time for analysis, and requires knowledge about the offering of each available system. Such prerequisites are often not fully available at manufacturing companies. Usually, upon approval of an investment in new information technology, the time dedicated for system selection is usually limited, as there is time pressure to begin implementation in order to achieve expected 
results and capture software benefits. Moreover, in most cases, although manufacturing companies are able to specify clear business requirements for the PLM, there is limited in house knowledge about the detailed offering of each PLM system available commercially, as this kind of knowledge is not needed for day-to-day business.

The problem that motivates the development of reference models for PLM systems is the difficulty faced by companies to evaluate and to compare existing PLM systems available in the market, in order to select the most appropriate alternative to fit their business processes needs. At the same time, for academic research, the main problem is to define the functional scope of PLM. There is still no widely accepted theoretical definition of the functions that should clearly belong to the scope of PLM or that should be considered in the business suites, such as ERP (Enterprise Resource Planning).

Aiming to fill these gaps, a reference model that represents the functions that are part of PLM systems scope was developed in earlier work carried out between 2006 and 2009 [1-2]. Practical application and discussion indicated need for improvement, such as adding new features and simplifying the model structure to facilitate its use. Additionally, since the model design, the technology offered by vendors has evolved considerably, indicating the need to update the model.

Based on the first version of the PLM reference model, a research project aiming to develop a new updated and enhanced version of the model was initiated in 2011. The updated PLM model should provide a common basis for comparison between different PLM systems available commercially, besides serving as a conceptual reference for the scope of PLM systems. This paper presents and discusses a preliminary proposal for the evolution of the PLM systems reference model.

The paper is structured in five sections. Section 2 presents the reference model of PLM systems in its 2009 version, which is being published for the first time in English. In section 3, major functional trends in PLM systems are discussed. Section 4 presents the preliminary proposal for the evolution of the PLM reference model. Finally, section 5 presents the main conclusions.

\section{$2 \quad$ PLM Reference Model}

This section starts with the definition of reference model and reference model types, followed by the presentation of the PLM reference model version 2009 [2].

\subsection{Reference Model Definition and Types}

The documentation of business processes may be performed by process models. A model is a representation of reality, usually with graphical notation, which describes the operation of processes in a logical, schematic manner. There are several methods for designing process models, and the degree of detail of a process model depends on the objective considered. Regardless of the possible semantic and notation variations, process models usually represent the following aspects: activities and their sequence, 
input and output information for each activity (information flow), organizational areas responsible for conducting each activity, and the resources used to perform the activities (e.g. a function of an information system).

A special class of business processes models is made up of more comprehensive models of wide application and benchmark character, called reference models.

Reference models of business processes are representations of business processes containing best practices. In addition, reference models are generic, so that they can reflect the reality found in various companies and various business situations. This allows reference models to be adapted for application in different contexts [3-4].

The specification of reference models can occur in two alternative forms. A reference model can be created inductively, based on the compilation of knowledge of several empirical cases and information systems. Alternatively, reference models can be deduced from the theory [3], [5].

In terms of application, reference models can be configured in specific models. The instantiation of a particular model from a reference model helps ensure that best practices are considered into the resulting model. With the use of reference models, it is expected that the deployment of specific models is faster and that the result is of better quality. Another possible application for reference models is in the evaluation of specific models. In this situation, the reference model provides a basis of comparison for identifying problems and opportunities for improvement in specific model [3], [6].

In addition to the reference models of business processes, there are other types of reference models. In the context of this paper, the reference models of information systems are relevant. These models represent the functions available in an information system [7], [8].

\subsection{PLM Reference Model v1.0 (2009)}

The PLM system reference model focuses on the functions used to support companies' business processes. It is, therefore, a reference model of systems' functionalities. Other aspects of PLM systems, such as supplier characteristics (e.g. size, geographical coverage, financial performance) are not considered.

Regarding its structure, the reference model of PLM systems is organized into four levels of detail: modules, groups of functions, functions and transactions. The four levels of detail are presented in three different views of the model. The first, a macroview, illustrates only the PLM system modules. The second view shows the modules and groups of functions. Finally, the third view of the model in tabular form comprises all the four levels of detail (Fig. 1). 
Modules view

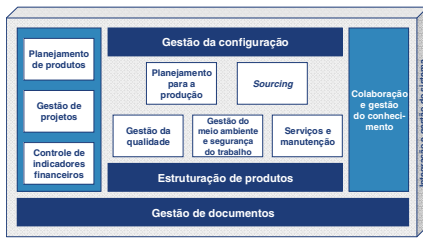

Modules and groups of functions view

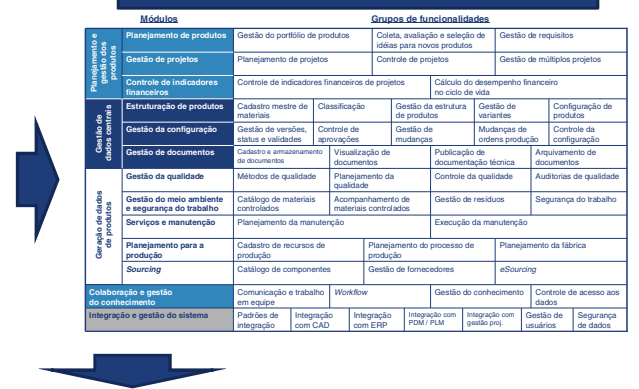

\section{Complete view (4 levels)}

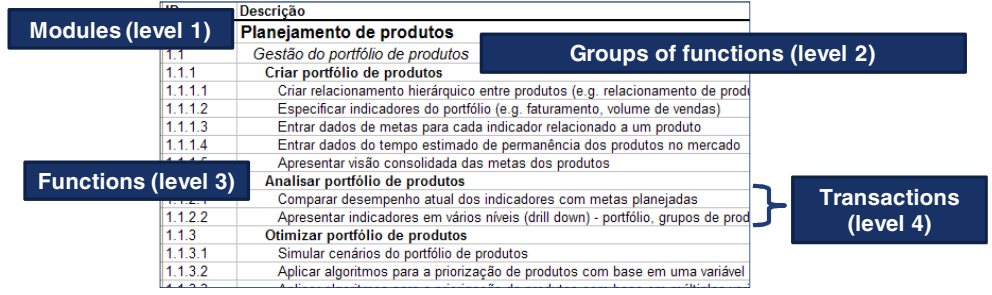

Fig. 1. PLM systems' reference model overview - three views and four levels of detail [2]

Given the structure of the reference model, the two broader views - modules and groups of functions - are described below.

At the first level of detail, the model consists of 13 modules, illustrated by Fig 2.

The layout of Fig. 2 indicates module role within the PLM system. On the left side of the figure, are displayed three modules related to the planning and management of product life cycle - product planning, project management, financial indicators.

In top and bottom of Fig. 2, are displayed the three modules related to central data management of the reference model - product structuring, configuration management and document management. These are the key modules for managing product data along the product life cycle.

In the center of Fig. 2, are presented modules focused on creating and specifying product data. These modules are focused essentially on the detailed specification of the products - quality management, environmental management, service and maintenance, production process planning and sourcing.

On the right hand side of Fig. 2 is displayed the module for collaboration and knowledge management, which includes functions that support teamwork, both internally within the company but also with partners in the extended value chain.

Finally, in the background of Fig. 2 is displayed the module integration and system management, which includes the necessary standards and interfaces to enable data exchange between PLM and other information systems. 


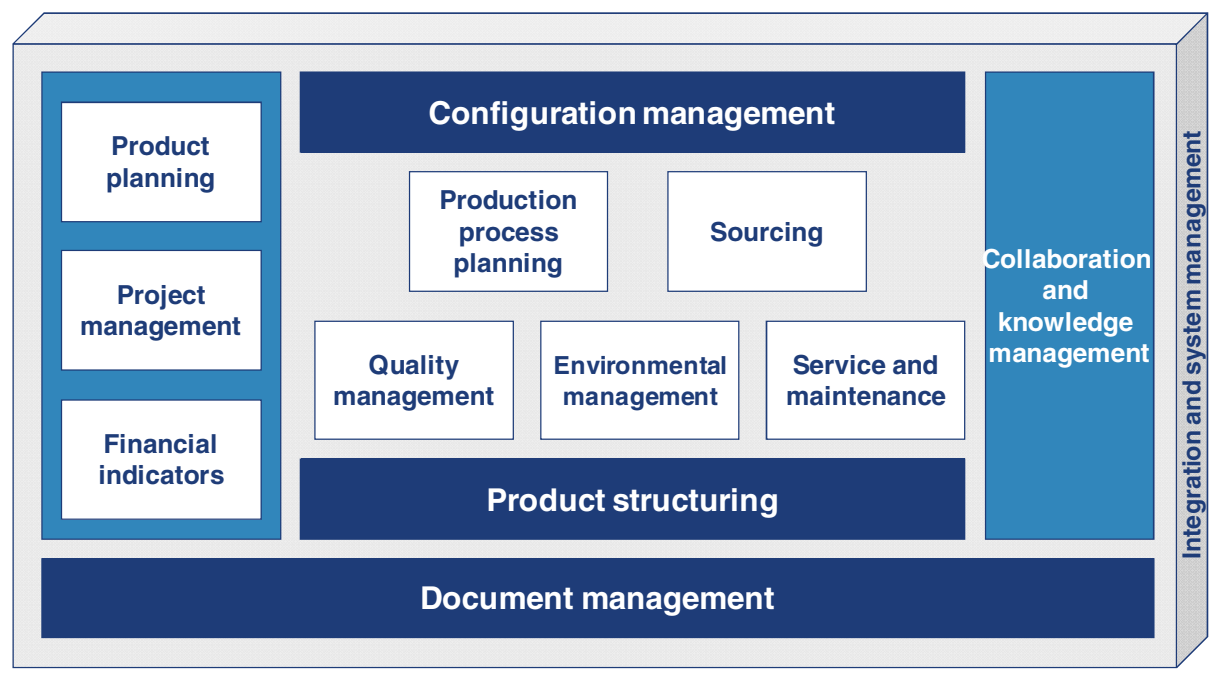

Fig. 2. Modules of the PLM reference model [2]

The 13 modules of the PLM systems reference model are, in turn, detailed in 49 groups of functionalities. The view of the reference model by modules and the corresponding groups of functions is presented in Table 1.

Table 1. Modules and corresponding group of functions of the PLM reference model [2]

\begin{tabular}{ll}
\hline Module & Groups of functions \\
\hline Product planning & Ideas management \\
& Requirements management \\
& Portfolio management \\
Project management & Project planning \\
& Project execution and control \\
& Project portfolio management \\
Financial indicators & Project controlling \\
& Lifecycle financial analysis \\
Product structuring & Parts management \\
& Classification \\
& Bill of materials \\
& Variant management \\
& Product configurator \\
& Version, status and validity management \\
Configuration management & Approval management \\
& Engineering change management \\
& Production order change management \\
& Configuration auditing \\
\hline
\end{tabular}


Table 1. (Continued)

\begin{tabular}{ll}
\hline Document management & Documents records \\
& Visualization \\
& Technical documentation \\
& Archiving \\
Quality management & Quality methods (e.g. FMEA) \\
& Quality planning \\
& Quality control \\
& Quality auditing \\
Environmental management & Hazardous materials catalogue \\
& Hazardous materials management \\
& Waste management \\
& Health management \\
Services and maintenance & Maintenance planning \\
& Maintenance execution and records \\
Production process planning & Production resources management \\
& Process planning \\
& Plant planning \\
Sourcing & External parts management \\
& Suppliers management \\
& eSourcing \\
Collanoration and know- & Communication \\
ledge management & Workflow \\
& Knowledge management \\
Integration and system & User data access management \\
management & Integration standards \\
& ERP integration \\
& CAD integration \\
& PDM / PLM integration \\
& Project management systems integration \\
& User management \\
Data safety
\end{tabular}

Additionally, a more detailed tabular view represents 296 functions and 1215 system transactions [2].

Following sections present the analysis of the latest trends in PLM systems and a preliminary proposal for the reference model revision.

\section{$3 \quad$ PLM Trends}

PLM systems have evolved within the limits set by other business applications. The boundaries of PLM are delimited with: CRM (Customer Relationship Management), used to manage customer data; SCM (Supply Chain Management), focused in production management and logistics; and ERP (Enterprise Resource Planning), with broad scope, including finance and HR management. 
Within these well recognized boundaries, PLM innovates in defining the product as the central element that is used to aggregate information from various sources. Moreover, PLM considers the complete lifecycle as the time dimension used to integrate information. As a result, any product information can be accessed directly by every authorized person at any time.

The identification of PLM trends focused most on functions offered to meet data management requirement throughout the entire product life cycle.

Data gathering for trends identification was based on the analysis of PLM offering from market leaders (Dassault Enovia, Oracle Agile, PTC Windchill, SAP PLM, Teamcenter Siemens), as well as analysis of market reports, including those of CIMdata. Data gathering occurred in the second half of 2011 and the early months of 2012.

Based on data gathered, four major trends that will impact PLM reference model were identified. These trends are detailed below.

Analytical Tools Based on Enhanced Software and Data Integration. PLM systems have been expanding the analytical capabilities to analyze costs and environmental impacts already at the very early stages of the lifecycle. These functions include the possibility of estimating product costs. Moreover, it includes the support for LCA (Life Cycle Analysis), applied to estimate environmental impacts (e.g. emissions and energy consumption) over the entire lifecycle. These functions are typically used in the earliest stages of product development, when design decisions dramatically influence costs and product environmental impacts.

Extended Service and Quality Functions. PLM has been gradually including functionality to support the more advanced stages of the lifecycle, such as maintenance management and spare parts management. Considering quality, software suppliers have been increasing the number of methods supported by PLM systems.

Regulatory and Materials Compliance. PLM has been adding features that support the assessment of compliance.

Collaboration. Social networks have been included in order to increase collaboration.

The trends identified and discussed above were considered in updating the PLM reference model, as discussed in the next section.

\section{Preliminary Proposal for Upgraded PLM Reference Model v2.0 (2012)}

The preliminary proposal for updating the reference model is presented in Table 2 . Items included are marked with an asterisk (*). Items that have changed positions are marked with two asterisks $(* *)$. 
On the modules level, three improvements were carried out to increase model coherence and logical structure: (1) creation of technical documentation module, which was previously a group of functions inside document management module; (2) creation of the utilities module, to group together all system management functions; (3) changing the name of the module focused on cost for Product cost analysis, emphasizing the role of cost estimate at the beginning of the cycle of life and reducing the importance of financial analysis that is still today not well covered in the scope of PLM.

At the second level (groups of functions), seven new groups were included (marked with *). In addition, four groups changed position (marked with **). Finally, four previously existing groups (Approval management, Hazardous materials management, Health management and Data safety) were distributed among most appropriate existing groups, to keep the logic and coherence of the whole model.

Table 2 presents a preliminary proposal for updating the PLM model.

Table 2. Modules and corresponding group of functons of the upgraded PLM reference model

\begin{tabular}{|c|c|}
\hline Module & Functional group \\
\hline \multirow[t]{3}{*}{ Product planning } & Ideas management \\
\hline & Requirements management \\
\hline & Portfolio management \\
\hline \multirow[t]{4}{*}{ Project management } & Project planning \\
\hline & Project execution and control \\
\hline & Project controlling $* *$ \\
\hline & Project portfolio management \\
\hline \multirow[t]{2}{*}{ Product cost analysis* } & Product cost estimation* \\
\hline & Lifecycle cost analysis* \\
\hline \multirow[t]{5}{*}{ Product structuring } & Parts management \\
\hline & Classification \\
\hline & Bill of materials \\
\hline & Variant management \\
\hline & Product configurator \\
\hline \multirow[t]{4}{*}{ Configuration management } & Version, status and validity management \\
\hline & Engineering change management \\
\hline & Production order change management \\
\hline & Configuration auditing \\
\hline \multirow[t]{2}{*}{ Document management } & Documents records \\
\hline & Visualization \\
\hline Technical documentation** & Technical documentation management** \\
\hline \multirow[t]{5}{*}{ Quality management } & Quality methods (e.g. FMEA) \\
\hline & Quality planning \\
\hline & Quality control \\
\hline & Quality auditing \\
\hline & Customer complaints* \\
\hline \multirow[t]{4}{*}{ Environmental management } & Materials catalogue \\
\hline & Lifecycle Assessment (LCA)* \\
\hline & Waste management \\
\hline & Regulatory compliance* \\
\hline
\end{tabular}


Table 2. (Continued)

\begin{tabular}{ll}
\hline Services and maintenance & Spare parts management* \\
& Maintenance planning \\
& Maintenance execution and records \\
Production process planning & Production resources management \\
& Process planning \\
& Plant planning \\
Sourcing & External parts management \\
& Suppliers management \\
& eSourcing \\
Collanoration & Communication \\
& Workflow \\
& Knowledge management \\
& Social networks* \\
& Integration standards \\
Integration & ERP integration \\
& CAD integration \\
& PDM / PLM integration \\
& Project management systems integration \\
& Archiving** \\
& User management** \\
\hline
\end{tabular}

The conclusions and next steps are discussed below.

\section{Conclusions and Next Steps}

This paper presents a reference model for PLM systems and discusses a preliminary proposal for the evolution of this model. At current research stage, data gathering about recent PLM trends has been concluded. Moreover, a preliminary proposal to improve the PLM reference model has been defined. Next steps include discussion of the proposal with academics and industry members, in order to refine the preliminary reference model update.

The reference model has been applied to support PLM software selection at the industry, defining a benchmark to compare different commercially available systems. Moreover, software suppliers may also take advantage of the reference model in order to identify gaps and define a development roadmap for the inclusion of new functionalities.

Acknowledgements. The author extends his sincere thanks to FAPESP (Fundação de Amparo à Pesquisa do Estado de São Paulo) for funding the research. 


\section{References}

1. Assmus, D., Meier, J., Treutlein, P., Zancul, E.S.: Marktspiegel Business Software - PLM / PDM 2006/2007. WZL Werkzeugmaschinenlabor der RWTH Aachen / Trovarit AG, Aachen (2006)

2. Zancul, E.S.: Gestão do ciclo de vida de produtos: seleção de sistemas PLM com base em modelos de referência. Escola de Engenharia de São Carlos, Universidade de São Paulo, São Carlos (2009)

3. Schwegmann, A., Laske, M.: Istmodellierung und Istanalyse. In: Becker, J., Kugeler, M., Rosemann, M. (eds.) Prozessmanagement. Ein Leitfaden zur prozessorientierten Organisationsgestaltung, pp. 155-184. Springer, Berlin (2005)

4. Fettke, P., Loos, P.: Using Reference Models for Business Engineering-State-of-the-Art and Future Developments. In: Innovations in Information Technology, pp. 1-5. IEEE, Dubai (2006)

5. Fettke, P., Loos, P., Zwicker, J.: Business Process Reference Models: Survey and Classification. In: Bussler, C.J., Haller, A. (eds.) BPM 2005. LNCS, vol.3812, pp. 469-483. Springer, Heidelberg (2006)

6. Vernadat, F.B.: Enterprise Modeling and Intergration: principles and applications. Springer, Heidelberg (1996)

7. Curran, T., Keller, G., Ladd, A.: SAP R/3 business blueprint: understanding the business process reference model. Prentice-Hall, Upper Saddle River (1997)

8. Keller, G., Teufel, T.: SAP R/3 Process Oriented Implementation. Addison-Wesley, Boston (1998) 